\title{
nature
}

physics

\section{Closed circle}

\section{CERN's latest accelerator is taking shape.}

The Large Hadron Collider is almost ready. With the sealing of the last interconnect in the cryogenic system on 7 November 2007, the ring is now complete. Cooling of the eight sectors of the ring is beginning, five by the end of 2007 with the remaining three to join the process early next year. A learning curve (and a steep one at that) has already been defined by the cooling, powering and then warming up of one sector earlier this year. Some statistics for the cryogenic system alone give an idea of the scale and complexity of this project: to cool 27-kilometres-worth of accelerator to 1.9 K involves 10,000 tonnes of liquid nitrogen and 130 tonnes of liquid helium coursing through 40,000 leak-tight welds.

Commissioning the machine from here on is an intricate process. The first injection of proton beams into the collider is scheduled for May 2008; circulating beams for June or July. "There is no big red button", says CERN Director General Robert Aymar - although he may wish there were. The recent history of the LHC might seem to be one of delays and disasters, with the 'turn on' date creeping, sometimes leaping, ever further into the future. In 2001, a major review pushed the price on the project higher; since then, the only contingency in the budget has been time.

Elsewhere in Europe, questions are being asked about burgeoning costs for the Galileo satellite system, a European counterpart to the American GPS. In the UK, there are warnings of time and cost overruns in several large-scale science projects; a parliamentary report ${ }^{1}$ bemoans a lack of available skill in project management.

Anyone concerned about the management of large scientific projects should look to CERN for a shining example. The LHC project has been characterized from the outset by a

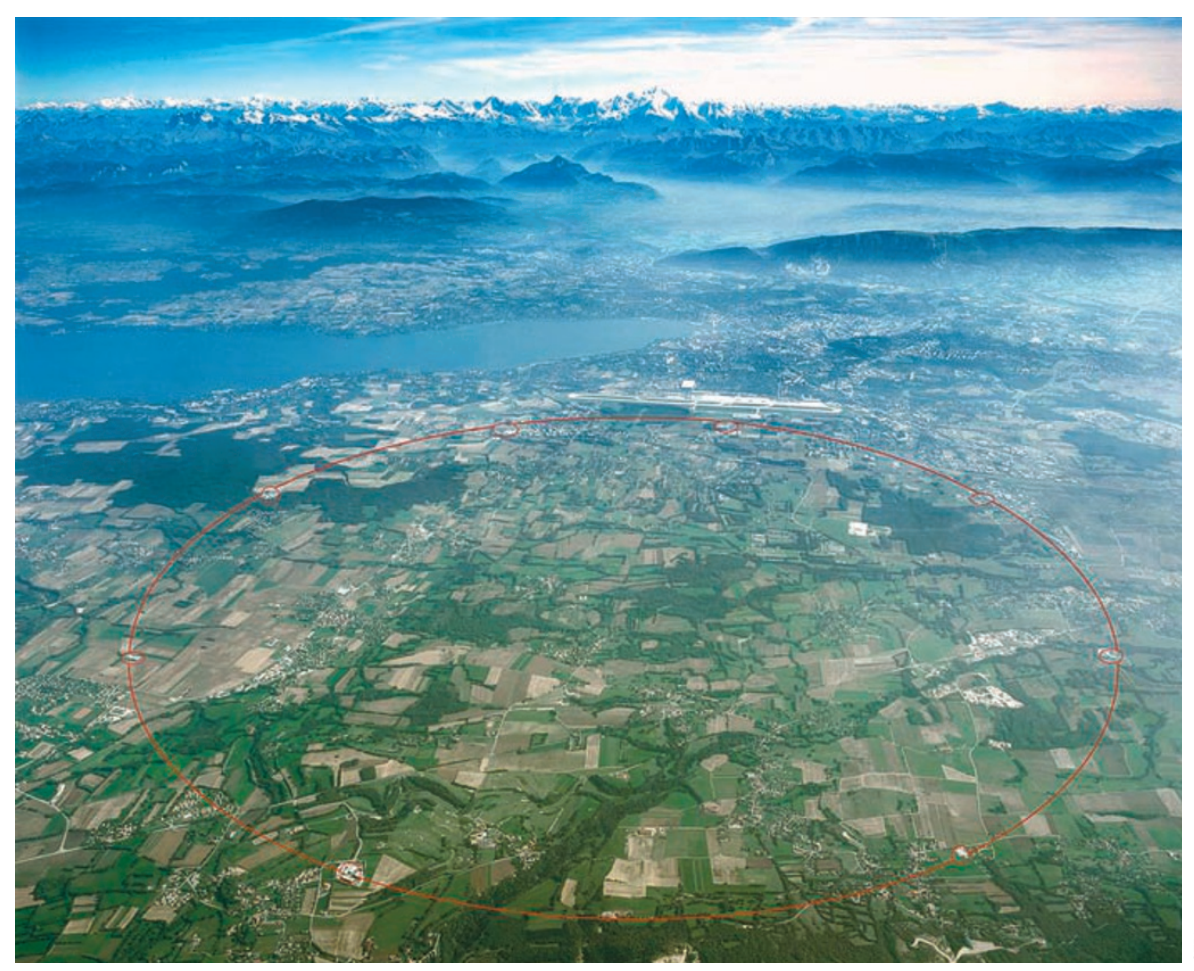

The ring of CERN's Large Hadron Collider — $27 \mathrm{~km}$ in circumference — is now complete, and ready for low-temperature commissioning.

huge level of commitment - from the physicists who made its case, to its champions in political circles, to those who negotiated the international partnerships that make this a truly global undertaking, to the engineers who are now putting the finishing touches to the vision. The history ${ }^{2}$ of the LHC is an interesting, not a perfect, one. There have been flaws in the plan, but that the LHC is now on course to turn on in 2008 is a triumph for all involved.

This level of worldwide investment in fundamental research is also to be celebrated. As Leon Cooper urges on page 824 of this issue, it must be recognized as the first step in creating a cycle of scientific progress and returns to the society that made that investment.

And as the year comes full-circle, here's to physics from the LHC in 2008.

\section{References}

1. House of Commons Committee of Public Accounts Big Science: Public investment in large scientific facilities HC521; http://www.publications.parliament.uk/pa/cm200607/cmselect/ cmpubacc/521/521.pdf

2. Llewellyn Smith, C. Nature 448, 281-284 (2007). 